\title{
Management Research on Reciprocity: A Review of the Literature
}

Markus Göbel, Institute of Organization and Logistic, Helmut-Schmidt-University of Hamburg, Germany, E-Mail: goebelm@hsu-hh.de Rick Vogel, Chair of Public Management \& Public Policy, Zeppelin University, Germany, E-Mail: rick.vogel@zu.de Christiana Weber, Institute of Management and Organizational Behavior, Leibniz University of Hannover, Germany,

E-Mail: christiana.weber@uni-hannover.de

\begin{abstract}
Although reciprocity is fundamental to all social orders, management research offers few reviews of the concept's theoretical origins and current applications. To help bridge this gap, we elucidate the dominant understandings of reciprocity, ask which areas of research emerge from them, and explore how they interconnect. Our bibliometric methodology detects four clusters of management research on reciprocity. Across these clusters, authors subscribe mainly to substantialist ontology, marginalize morally oriented motives consistent with relational ontology, and largely assume that benefit-oriented motives underlie reciprocity. We outline the advantages of a moral-oriented relationalist concept of reciprocity and discuss potential areas for its development in management research.
\end{abstract}

JEL classification: F38, K22, G52

Keywords: benefit orientation; bibliometrics; bibliographic coupling; citation analysis; morality; network analysis; ontology; practice theory; reciprocity; social exchange

Manuscript received November 11, 2011, accepted by Peter Walgenbach (Management) December 21, 2012

\section{Introduction}

Reciprocity is a norm of action fundamental to all social orders (Mauss 1990). In management research, numerous studies on psychological contracts, organizational citizenship behavior, joint ventures, and corporate networks show that reciprocity plays a leading role in governing interaction both within and between organizations (Dabos and Rousseau 2004; Göbel, Ortmann, and Weber 2007; Larson 1992; Muthusamy and White 2005; Robinson and Morrison 1995). Yet despite this broad relevance of reciprocity to management research, few attempts have been made to review the concept's theoretical origins and current applications systematically. What are the dominant understandings of reciprocity, which areas of research emerge from them, and how do these subfields interconnect? The lack of clear answers to these questions is compounded by the fact that reciprocity is a construct frequently implicit in social inquiry; it is a construct resting on basic assumptions that are often only tacit. To improve the understanding of reciprocity, our aims in this review are (i) to reveal the concept as treated in the current literature, (ii) to explore the fields of research that emerge from it, and (iii) to outline how a relational approach to reciprocity routed in social theory can contribute to future investigation.

Derived from the Latin reciprocare - moving or flowing back and forth - the word reciprocity is defined in this paper as a form of interaction that essentially centers on mutuality. The underlying motives for action are constitutive for all forms of mutuality. We therefore differentiate between forms of reciprocity based on benefit and those based on obligation, or duty. Like Mauss (1990) and Göbel, Ortmann, and Weber (2007), we refer to reciprocity stemming from calculations of benefit as "exchange"; reciprocity stemming from a sense of obligation or duty, as "giving." This distinction is analyt- 
ical. In practice, there are only hybrid kinds of exchange and giving. Purely utilitarian exchange and purely obligatory giving are ideal types; they do not appear empirically.

Our definition of reciprocity as motivationally interrelated actions is deliberately broad which allows drawing on Mauss (1990) and Polanyi (1944) - to depict the literature's actual spectrum of implicit and explicit definitions. Under the umbrella of this broad understanding of reciprocity in the literature one finds in particular two related concepts, social exchange and economic exchange, which we want to mention at this point as much of management research pivots on them. Both concepts are fundamentally characterized by a clear benefit orientation: "In the purest examples, actions are motivated by self-interest and unaffected by social or moral considerations beyond the self-interested morality of 'greed is good"' (Biggart and Delbridge 2004: 36). Every relationship involving exchange or cooperation is explained in crude functionalist terms - their effects that minimize transaction costs and thereby increase the adaptability and economic stability of the system. Blau (1964), a major exponent of social exchange theory, distinguished this economic exchange from social exchange (Cropanzano and Mitchell 2005): "The basic and most crucial distinction is that social exchange entails unspecified obligations" (Blau 1964: 93). He held that social exchange has to do with "voluntary actions of individuals that are motivated by the returns they are expected to bring and typically do in fact bring from others" (p. 91). Only social exchange "involves favors that create diffuse future obligations, ... and the nature of the return cannot be bargained" (p. 93) and "tends to engender feelings of personal obligation, gratitude, and trust; purely economic exchange as such does not" (p. 94). According to Ekeh (1974), however, Blau's psychological terminology cannot obscure "the crucial importance of economic motivation in his social exchange theory" (p. 169; see also Molm 2003). As a proponent of the rational action model, Ekeh (1974) regarded an exchange relation as a series of strategic games based on practical utilitarian calculations.

In our broad conceptualization of reciprocity, social and economic exchange figure prominently, but they are not universal forms of the relationship. They both key in on utilitarian motives, which account for only some kinds of reciprocity. The literature contains selective overviews and detailed sum- maries of them and of other principal dimensions of reciprocity (e.g., Cropanzano and Mitchell 2005). However, we know of no research in either management or its related fields that gives an overview of the construct of reciprocity as a whole. The goal of this paper is to do just that. Although we direct our attention chiefly to management literature, we include the relevant contributions in neighboring disciplines (economics, psychology, sociology, and anthropology) because they provide important foundations for reciprocity research in the field of management as well.

We hence begin with an interdisciplinary perspective that outlines the origin of the reciprocity concept in the social sciences. The subsequent review narrows the focus to management research on reciprocity. It is based on a bibliometric methodology that permits a systematic approach to the burgeoning literature in the field of management. We then conduct and report the results of bibliometric analysis of our data. That presentation is followed by a description of what reciprocity is understood to mean in the clusters of research that emerge from the bibliographic network. In the discussion, we derive the definition of reciprocity that is most widely accepted in current management research and develop, in addition, an alternative, much less acknowledged notion of reciprocity. We elucidate the opportunities for integration of the new definition of reciprocity in organization studies research. It is particularly in social network theory, complexity theory and institutionalism that we identify potential for advancement and enrichment of research by means of this less widely accepted notion of reciprocity.

\section{Reciprocity in the Social Scien- ces}

Reciprocity is the basis of all social relations. "Understanding reciprocity is indispensable for understanding all social forms, such as communities, organizations, families, and political systems" (Kolm 2008: 5). Accordingly, the construct is widely encountered in the social sciences, as shown by a search for the term reciprocity in titles, abstracts, and keywords of published academic articles and reviews listed in the Social Science Citation Index ${ }^{\circledR}$ (SSCI), excluding editorial materials, proceedings papers, book reviews, and similar texts (Figure 1). The number of hits in the SSCI's subject categories 
Figure 1: Number of journal articles on reciprocity in the Social Science Citation Index, 1990-2008

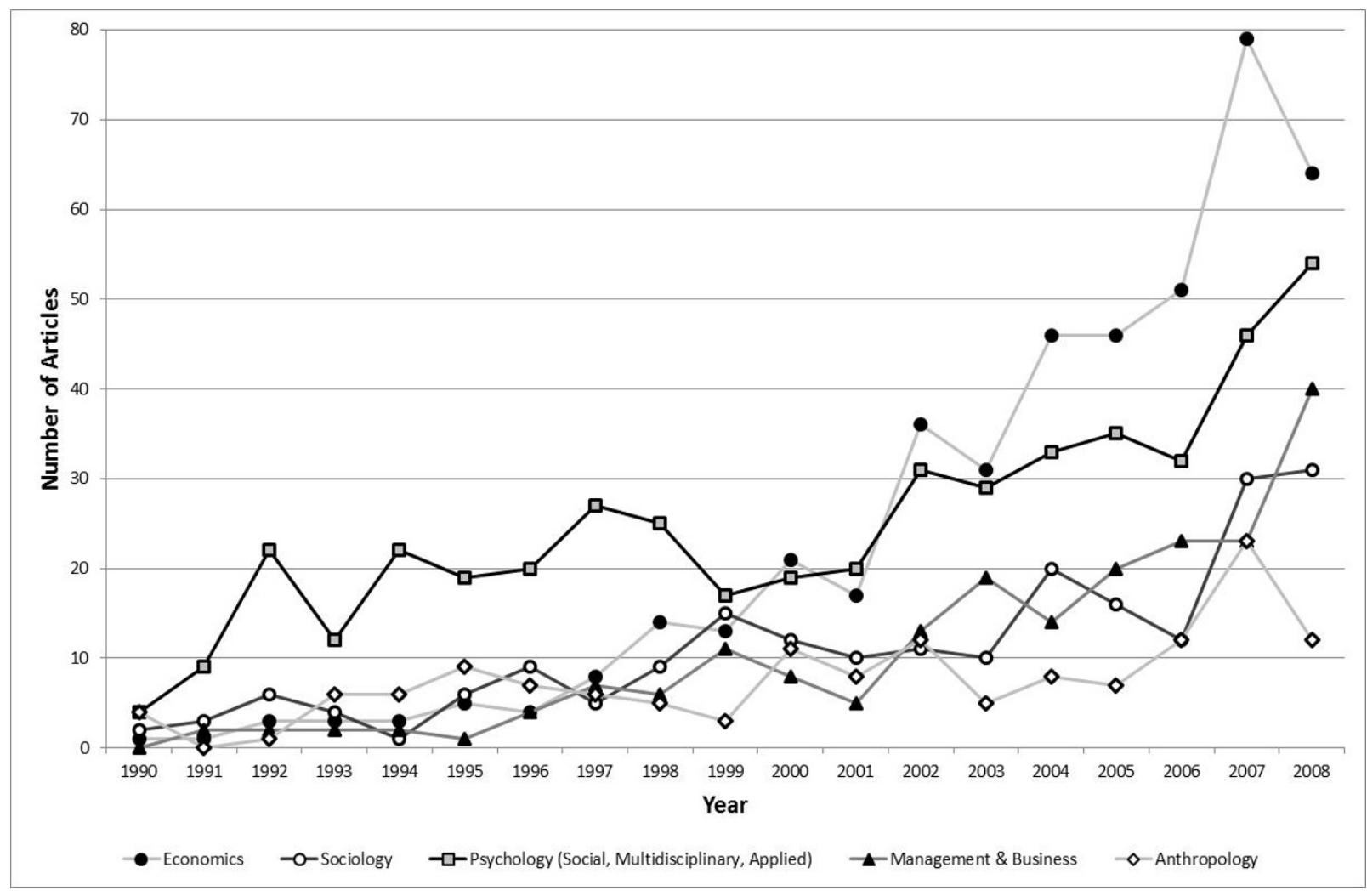

suggests that psychology, economics, sociology, management and business, and anthropology are the primary fields of reciprocity research. The priorities in these disciplines have shifted over time. In the 1990 most contributions came from psychology - a finding we attribute to the extremely wide application of the reciprocity concept in that discipline, which encompasses areas of inquiry ranging from clinical psychology and gerontology to organizations and management. Since the turn of the millennium, however, economics has led the research on reciprocity. We believe this rapid ascendance is due to the soaring number of publications in quantitative empirical and experimental research in economics, a field in which the hitherto accepted action model rational choice - is being challenged and empirically expanded. Contributions from the other disciplines, including management and business, have numerically increased at a moderate pace (partly because their databases give wider overall coverage than do those in economics). Our analysis of publication volume clearly shows that reciprocity is a fundamental concept anchored in a variety of social sci- ences. However, the history of the construct differs from one discipline to the next. To trace these traditions bearing on the study of reciprocity, we conducted a simple citation analysis that identified the core literature in the dominant branches of research. The ranking in Table 1 is based on the "classical" works, those most frequently cited in the journal articles tracked in Figure 1.

The various contributions have not only introduced different forms and motives of reciprocity into the literature but also argue on different ontological levels (Figure 2). Researchers attempting to classify the various motives have entertained a number of viewpoints, including altruism versus egoism (Fehr and Fischbacher 2003, 2005; Fehr and Gächter 2000; Fehr, Kirchsteiger, and Riedl 1993; Fehr and Schmidt 1999; Fehr, Fischbacher, and Gächter 2002), social distance versus personal relation between the transaction partners (Blau 1964; Granovetter 1973; Sahlins 1972; Simmel 1950), the temporal interval (immediacy or delay) between giving and taking (Bourdieu 1990), the equivalence of the gifts (Bourdieu 1998; Gouldner 1960; Homans 
Table 1: Top-ten Journal Articles on Reciprocity: Frequency of Citation in Various Disciplines

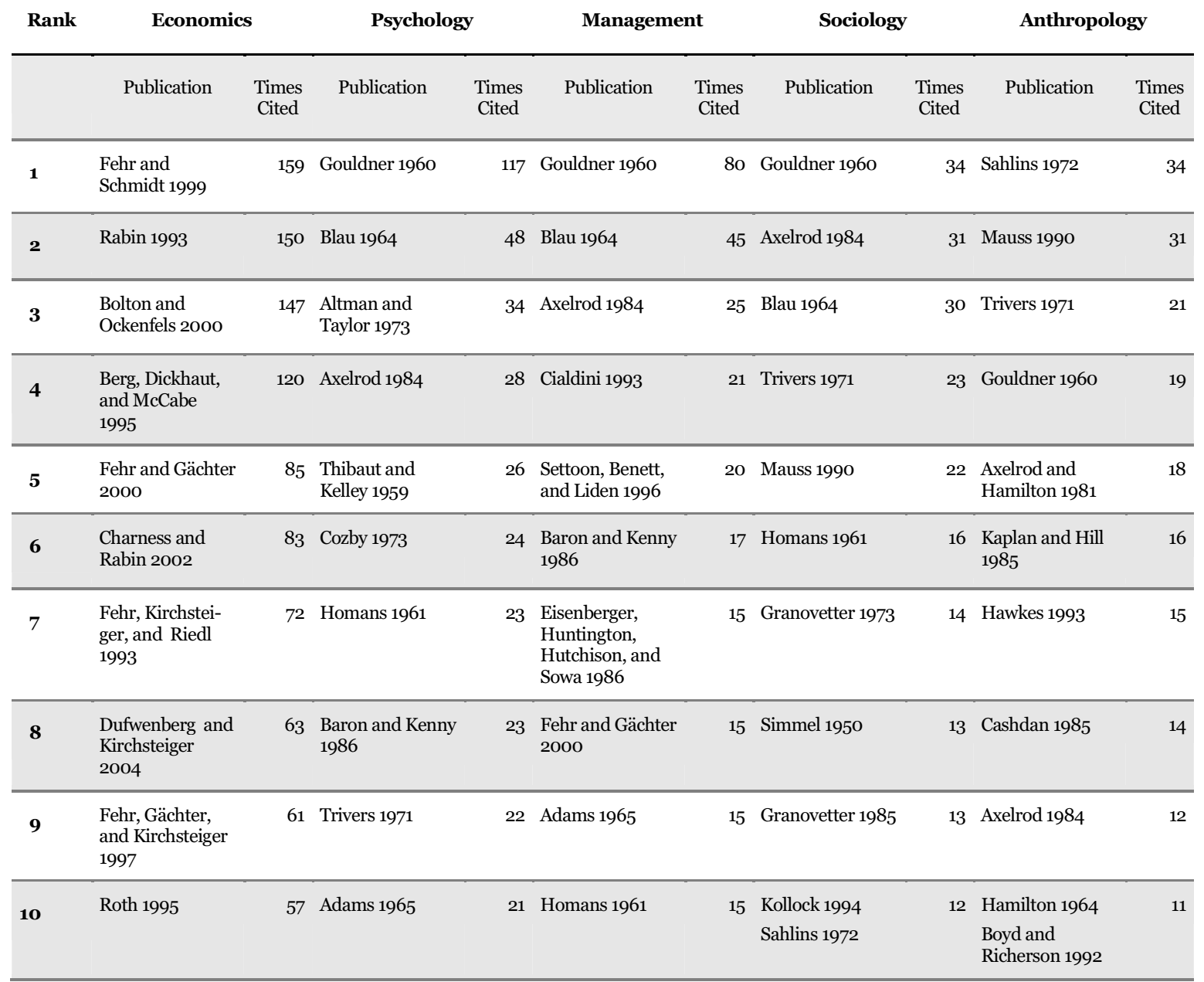

1961), the likelihood that a gift will be given in return (Axelrod 1984; Berg, Dickhaut, and McCabe 1995), and voluntariness and generosity (Mauss 1990). Referring to equivalence, for example, Gouldner (1960) distinguished between homeomorphic and heteromorphic reciprocity. Clustering the aspects of altruism, egoism, and immediacy (or delay), and the personal (or impersonal) nature of the relations between the transaction partners, Sahlins (1972) distinguished between generalized, balanced, and negative reciprocity. Using the concept of altruism somewhat like Sahlins (1972) did, Fehr and Fischbacher (2003) strove to underscore "human altruism" in their concept of "strong reciprocity" as "a powerful force" (p. 785; see also Fehr, Fischbacher, and Gächter 2002).

The motives underlying exchange and reciprocity stand out as a fundamental question across the disciplines represented in the currents of the literature we have consulted. Although not one of the most frequently cited works in economics as far as research on reciprocity is concerned, The Wealth of Nations (Smith 1776/1976) stresses that welfareenhancing exchange is based on a utilitarian mindset of the actors participating in it. "It is not from the benevolence of the butcher, the brewer, or the baker, that we expect our dinner, but from their regard to their own interest. We address ourselves, not to their humanity but to their self-love, and never talk to them of our necessities but of their advantages" (pp. 26-27). Whether a matter of labor relations, cooperation between companies, or consumer relations, the give and take that cooperation entails is understood to mean exchange (under certain conditions, delayed exchange) and is generally ascribed to utilitarian deliberations on the part of 
the participants. Smith (1776/1976), however, pointed out the necessity of moral action, without which market exchange would be impossible: "It is not the love of our neighbour, it is not the love of mankind, ... It is a stronger love, a more powerful affection, which generally takes upon such occasions; the love of what is honourable and noble, of the grandeur, and dignity, and superiority of our own characters" (p. 212).

This complementary view from Smith's moral philosophy on the way political economies function has received little attention in economics and social science. Most economists (e.g., Güth 1995; Hirshleifer 1988; Kreps, Milgrom, Roberts, and Wilson 1982; Williamson 1993) and many sociologists (e.g., Axelrod 1984; Coleman 1990) assume that every cooperative relationship is reducible exclusively to underlying calculations of benefit. According to their assumption, human behavior is in all social interactions driven by utilitarian motives. Management theorists who have thought about the facilitation, regulation, and coordination of cooperation (e.g., Kogut 1989) usually speak of incentives and controls - again, of utility. Even those sociologists (Gouldner 1960), ethnologists (Levi-Strauss 1969; Trivers 1971), and cultural anthropologists (Sahlins 1972) who do see an indispensable moral code of give and take at work are apt to confine this construct to the "gift exchange" in so-called tribal societies, as highlighted by Malinowski (1949) and others, especially Mauss (1990). However, closer examination behind the veil of normative discourse by economists and utilitarian moralists ultimately shows that human beings act for mixed reasons, including obligation to themselves and to others (Polanyi 1944).

An example is found in the field of interorganizational management studies. Although competition is the overriding subject of this literature (for example, Cable and Shane 1997; Lado, Boyd, and Hanlon 1997; Parkhe 1993; Von Hippel 1987), the discussion of networks entails dimensions of cooperation or "co-opetition" (e.g., Nalebuff and Brandenburger 1998), and, concomitantly, of reciprocity based on more than benefit. In particular, Powell (1987) was more pointed than many scholars in seeing these facets as the crucial characteristic of such "hybrid" forms of coordination: "In several important respects, hybrid forms represent a modern version of a centuries-old means of allocating goods and services, a method that Polanyi termed 'generalized reciprocity" (p. 81). In other words, the transaction takes place neither as a discrete exchange nor as a response to an administrative dictate but rather due to established norms of reciprocity - a fact that has been confirmed by numerous studies, particularly in interorganizational cooperation.

Regardless of whether it takes the form of an exchange, dictate or a norm: reciprocity remains a fundamentally or constitutively relational construct. Emirbayer (1997) was preoccupied with this relational aspect in his theoretical paper on different ontological positions in social sciences, in which he described the construct of relationalism. This construct focuses on reciprocal processes of perception and interaction through space and time, and is opposed to the construct that Emirbayer calls substantialism. In line with Cassirer (1953) and Dewey and Bentley (1949) Emirbayer (1997) ontologically provides a basis for distinguishing between two principal positions in social science research: substantialism and relationalism (Figure 2). In substantialism, substances of various kinds (things, beings, essences) constitute the fundamental units of all inquiry. "Systematic analysis is to begin with the selfsubsistent entities, which come 'performed', and only then to consider the dynamic flows in which they subsequently involve themselves" (Emirbayer 1997: 283). "Relation is not independent of the concept of real being; it can only add supplementary and external modifications to the latter, such as do not affect its real "nature"' (Cassirer 1953: 8). In this context Dewey and Bentley (1949) differentiated the substantialist approach into two separate subcategories that usually inform the underlying literature of the present study in one way or another. The first is what they termed the perspective of self-action, by which one conceives of "things ... as acting under their own powers" (Dewey and Bentley 1949: 108). In social science this notion of self-action is known as methodological individualism. It is the theoretical basis for all types of games in rational choice theory, including game theory. Though the relations between actors initially seem to be the main analytical interest, the substantialist thrust of research on game theory is clear in the articles we have read in that field. "Here again, pre-given entities are seen to generate self-action; even as actors engage in game 
Figure 2: 'Classical' works on reciprocity in the social sciences

\section{Benefit}

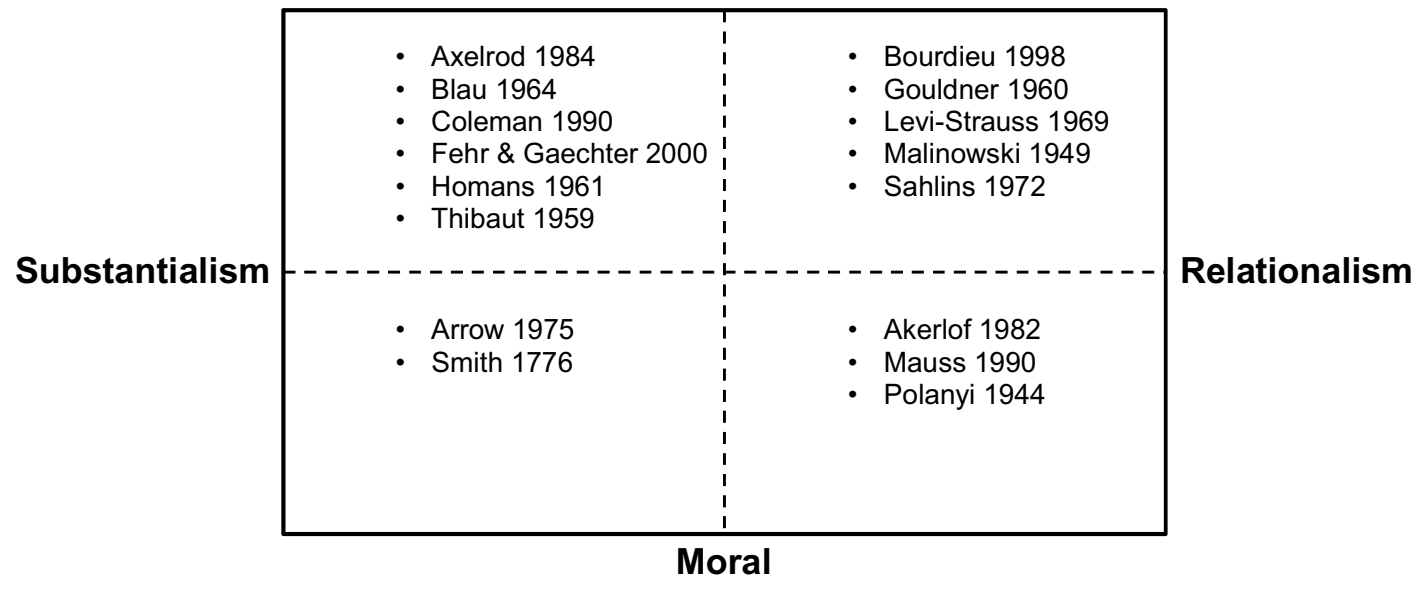

playing with other actors, their underlying interests, identities, and other characteristics remain unaltered" (Emirbayer 1997: 284). In the articles we examined for the present study, a substantialist kind of research that Dewey and Bentley (1949) called interaction is even more common than rational choice approaches are. The substantialist approach, which is frequently confounded with more truly relational points of view, posits "thing as balanced against thing in causal interconnection" (Dewey and Bentley 1949: 108), where entities no longer generate their own action, but rather the relevant action takes place among the entities themselves. "Entities remain fixed and unchanging throughout such interaction, each independent of the existence of the others, much like billiard balls or the particles in Newtonian mechanics" (Emirbayer 1997: 285-286). The prototype of this form of substantialism appears in the so-called variable-centered approach. It features, as Abbott (1988) pointed out, a compelling imagery of fixed entities with variable attributes that "interact, in causal or actual time, to create outcomes, themselves measurable as attribute of the fixed entities" (p. 170).

A relational perspective is fundamentally opposed to both varieties of substantialism. It is a perspective of transaction "where systems of description and naming are employed to deal with aspects and phases of action, without final attributes to 'elements' or other presumptively detachable or independent 'entities', 'essences', or 'realities', and without isolation of presumptively detachable 'relations' from such detachable 'elements"' (Dewey and Bentley 1949: 108). From this point of view, the very terms of units involved in a transaction derive their meaning, signifi- cance, and identity from the changing functional roles they play within that transaction. Seen as a dynamic, unfolding process, the transaction, rather than the constituent elements themselves, becomes the primary unit of analysis. Hence, relational theorists reject the notion that one can posit discrete, pre-given units such as the individual or society as starting points of analysis. The emergence of individual motives and strategies for action, therefore, cannot be divorced from the transactional context in which the individual actor is embedded. Actors thus do not enter into reciprocal interaction with a particular order of preferences and action strategy. Rather, those preferences and strategies come about in the wake of mutual processes of recognition. "Agency is always a dialogic process by which actors immersed in the durée of lived experience engage with others in collectively organized action contexts, temporal as well as spatial" (Emirbayer 1997: 294). Pizzorno (1991) stated that individual identities are thus constituted within "circles of recognition" (p. 219), while interests (a secondary construct) "grow out of different positions in the[se] networks and circles" (p. 219). Such circles of recognition can include 'virtual' circles with cultural ideals and fantasized objects, as well as circles of interpersonal social relationships (pp. 296-297). Figure 2 summarizes the substantialist and relational dimensions and categorizes their proponents according to their basic understanding of reciprocity.

This cursory review of the literature documents not only that reciprocity is broadly relevant to the social sciences, as indicated by the number of related publications in various disciplines, but also that both benefit (i.e., utility) and morality are operative as 
motives for action, with benefit being the dominant one. We now turn our attention to a bibliometric analysis of the literature pertaining to management research on reciprocity.

\section{Data and Methodology}

Bibliometric studies apply statistical methods to large-scale bibliographic databases in order to help assess scientific communication through formal publication channels (Leydesdorff 2001). The reason for launching bibliometrics as a scientific field (De Solla Price 1965; Garfield 1955; Pritchard 1969) is more pressing than ever, for in the culture of "publish or perish" it has become increasingly difficult to keep track of all the publications in the rapidly growing body of scientific literature. Bibliometric methods are particularly helpful in fields where research based on a given construct emerges in distributed clusters whose mutual relationships are unclear. This applicability is likely for the construct of reciprocity, whose prevalence in management research owes to the fundamental role that reciprocity plays in much of social and economic life.

The data of our analysis were compiled from the above-presented results of a keyword search for reciprocity in SSCI (Figure 1). To ensure the relevance of our review for management research, we reduced these data to journals classified under the subject areas of "Management" and "Business". Because many journals fall into more than one subject category, research at the interface with other fields of specialization (such as psychology, sociology, and economics) was considered to some extent, too. The final database of the bibliometric study consisted of 232 documents published from 1956 through the first half of 2009, with 12,423 references to 6,535 sources.

To these data we applied the imaging method of bibliographic coupling (Kessler 1963). A bibliographic coupling is an intertextual relationship that is established when at least two documents refer to the same other text. In other words, publications are coupled when the reference list of one overlaps with that of the another. The more references they have in common, the more tightly they are coupled, and the more similar they are assumed to be. The indicator is thus used as a measure of document similarity (Ahlgren and Jarneving 2008). The basic assumption is that texts are in some way similar to each other when they are built on the same sources. In technical terms, the result of bibliographic coupling is a similarity matrix that displays co-occurrences of references. By applying this method, one conducts the analysis at the level of citing rather than of cited documents. Because a given text is more recent than the sources it cites (except for sources cited as in press), the method is used to capture present trends rather than past traditions of the field under study (Jarneving 2005, 2007). However, bibliographic coupling is not an impact measure, for it is based on the references made by the analyzed document rather than on the references made to it.

To enhance the robustness of the results, we applied relative rather than absolute measures of document similarity. As has been shown for co-citation analysis (Gmür 2003), this procedure produces better results in the course of the subsequent clustering of documents than raw frequency counts. We thus divided the number of couplings between any two documents by the sum of all references in the according bibliographies. The resulting similarity matrix was then converted with network analysis into a map of reciprocity research in the field of management. This network diagram depicts relevant publications (as nodes) and their relationships in terms of bibliographic couplings (as edges). To render the visual information comprehensible, we considered only nodes with a bibliographic overlap of at least $6 \%$ with at least two other nodes. Both thresholds were met by 85 publications, with the network core consisting of the most interrelated documents.

To arrange the nodes in a two-dimensional space, we applied the spring embedder algorithm provided by the software package UCINET by Borgatti, Everett, and Freeman (2002), which is similar to multidimensional scaling approaches. The graph layout algorithm optimizes distances between every pair of nodes. The distances between nodes are approximated by the path length (the number of edges between them). The shorter a node's mean path length is to other nodes, the higher its centrality in the network. To detect subfields of nested publications within the network, we applied a hierarchical clustering of network components as provided by UCINET for valued graphs (Borgatti, Everett, and Freeman 2002). 


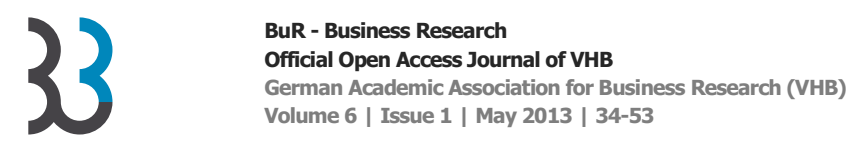

Figure 3: Network of bibliographic couplings of articles on reciprocity ${ }^{1}$

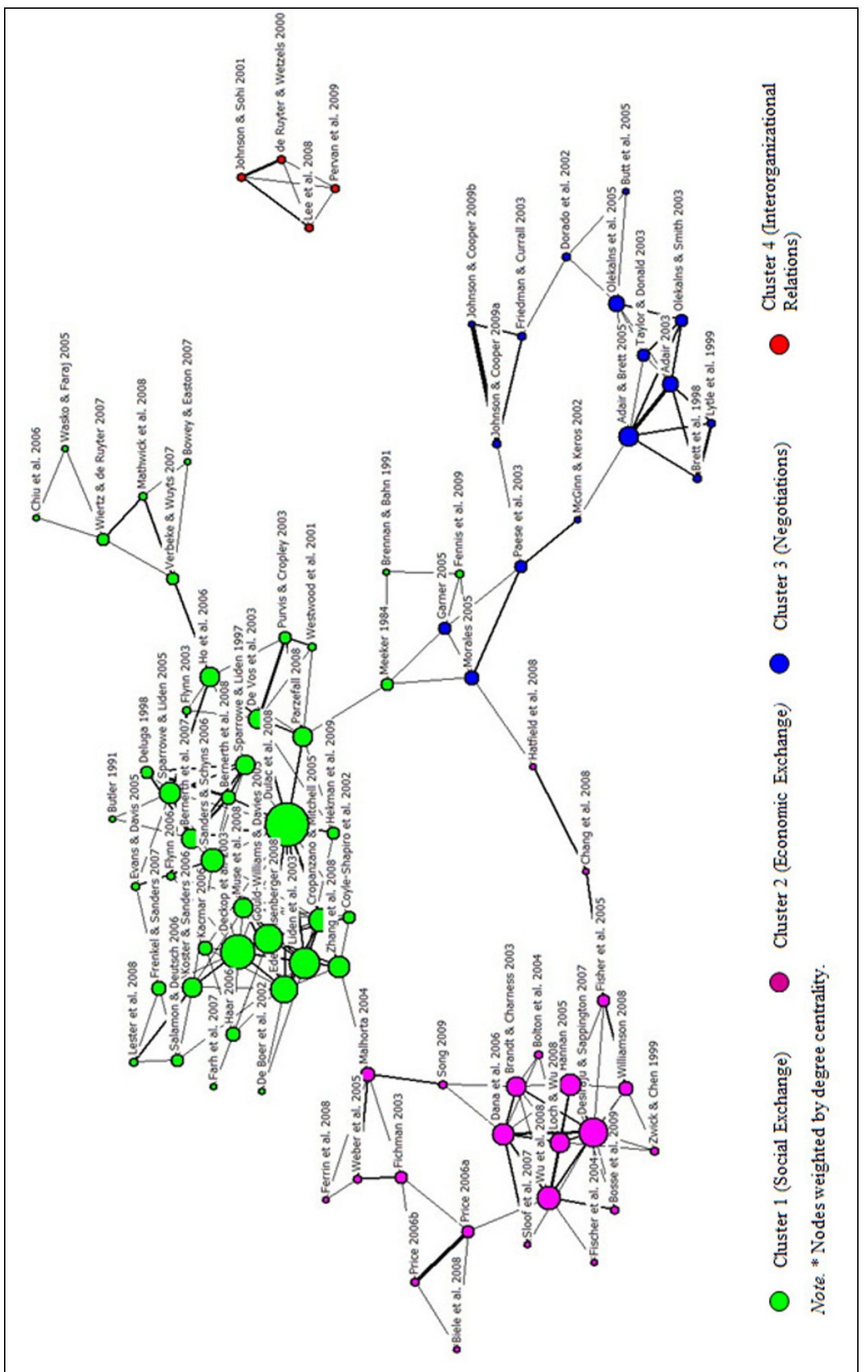




\section{Results: Management Research on Reciprocity}

The bibliographic network of reciprocity research in the field of management is depicted in Figure 3 (online available in a higher resolution: http:// www.business-research.org/portal_skins/custom/ early_view/kopplung_reciprocity_revised_2.jpg). The thickness of the edges in the network is proportional to the bibliographic couplings in terms of relative measures, while the node size is proportional to the degree (i.e., the number of ties to other nodes). The more interconnected a node is, the bigger is the symbol in the diagram. The extracted network components are indicated by different node colors. Four clusters of publications compose the field of management research on reciprocity. Subsequently, we elucidate these priorities in contemporary research on reciprocity by analyzing and interpreting the extracted components. We outline these bodies of literature only briefly in order to highlight their key features.

\subsection{Cluster 1: Social Exchange}

The first cluster, including 42 publications, is strongly rooted in social and organizational psychology. Assigned papers share an interest in social exchange (Cropanzano and Mitchell 2005), but differ in the ways they approach this topic. A couple of articles focus on reciprocity in social exchange among employees, most prominently on helping and co-working behavior (Deckop, Cirka, and Andersson 2003; Flynn 2006; Frenkel and Sanders 2007; Koster and Sanders 2006). Norms of reciprocity are important drivers of cooperation in organizations, as helping behavior largely depends on the degree to which employees receive assistance from their colleagues. While this stream of research highlights reciprocity in horizontal relationships among organizational members, other works focus on vertical relations in leader-member exchange (LMX; Bernerth, Armenakis, Feild, Giles, and Walker 2007, 2008; Deluga 1998; Sparrowe and Liden 1997). Since reciprocity is an important quality characteristic of supervisor-subordinate relationships, the predictors of reciprocal LMX, such as social structure or personality traits, attract most of the authors' attention. While the literatures on coworking behavior and LMX focus on interpersonal reciprocity within or across hierarchical levels, further works in the social exchange cluster relate reciprocity at the individual level to organizational phe- nomena at the collective level. For example, several papers examine how organizational citizenship behavior (Lester, Meglino, and Korsgaard 2008; Liden, Wayne, Kraimer, and Sparrowe 2003; Salamon and Deutsch 2006), positive organizational behavior (Muse, Harris, Giles, and Field 2008) and trust (Butler 1991; Meeker 1984; Sanders and Schyns 2006) evolve from reciprocity in relationships among organizational members and, in turn, foster reciprocal behavior. Furthermore, both the literature on psychological contracts (De Vos, Buyens, and Schalk 2003; Ho, Rousseau, and Levesque 2006; Parzefall 2008; Purvis and Cropley 2003; Westwood, Sparrow, and Leung 2001) and on perceived organizational support (Eder and Eisenberger 2008; Fahr, Hackett, and Liang 2007; Haar 2006; Hekman, Bigley, Steensma, and Hereford 2009) showed that reciprocal behavior of members is strongly affected by the quality of their relationship to the organization, as the extent to which they do or do not adhere to reciprocity norms depends on perceptions of organizational support or psychological contract violation. Some papers in this cluster highlight the role of reciprocity as contextual variable in the emergence and development of psychological contracts and advance the understanding of reciprocity as residing in collective beliefs inside and outside the organization (Ho, Rousseau, and Levesque 2006; Parzefall 2008; Westwood, Sparrow, and Leung 2001). The latter view deviates to some extent from the mainstream by tracing reciprocity to cultural understandings of morality, while most other works in the social exchange cluster agree on a utilitarian concept of reciprocity, associated with the trading of mutual contributions for future benefits.

\subsection{Cluster 2: Economic exchange}

The second cluster, consisting of 23 articles, does not fundamentally depart from the first cluster, but has some different theoretical and methodological orientations as well as thematic emphases. Just like the social exchange cluster, assigned papers predominantly focus on reciprocity in exchange relationships, but they do so from a decisive economic perspective. The most obvious thematic overlap with the social exchange cluster is the preoccupation with trust (Ferrin, Bligh, and Kohles 2008; Malhotra 2004; Weber, Malhotra, and Murnighan 2005). By considering trust to be a condition that enables viable cooperation, according papers come 
closest to the social exchange cluster (Figure 1). However, the economic branch of trust research relies on an interactional understanding of trust, that is, the conviction that trustors and trustees find themselves in a dyadic reciprocal relationship in which one of the exchange partners gives trust and the other receives it. This approach largely complies with the notion of calculative trust, while works in the social exchange cluster additionally consider other forms such as personal and societal trust (Williamson 1993). Further similarities to the literature on social exchange exist in papers on social preferences and concerns for others (e.g., Chang, Cheng, and Trotman 2008; Fischer, Irlenbusch, and Sadrieh 2004; Loch and Wu 2008). This body of research provides some evidence that cooperative behavior is often triggered by intrinsic concerns for others' welfare rather than by economic incentives. However, pro-social behavior is limited as it often fails to achieve the social optimum (Fischer, Irlenbusch, and Sadrieh 2004) and may also arise from a desire not to violate the expectations of exchange partners (Dana, Cain, and Dawes 2006). When actors engage in economic exchange, they adjust the degree of reciprocation to contextual influences such as firm profit (Hannan 2005). A more distinct subgroup of research in the economic exchange cluster emerges from several papers on fairness. This research shows that economic actors respond to perceived fairness with reciprocal behavior which enhances cooperation among group members (Bosse, Philipps, and Harrison 2009; Williamson 2008). More cooperative (i.e., higher-contributing) members are more favorably evaluated than less cooperative (i.e., lower-contributing) members (Price 2006a, b). Despite these benefits of cooperation both for individual reputation and for organizational outcomes, rules of reciprocity are often violated by unfair actions in general and free-riding more specifically (Wu, Loch, and Van der Heyden 2008). These violations suggest that fairness is subject to cost-benefit evaluations (Zwick and Chen 1999). This emphasizes again that works in the economic exchange cluster strongly rely on assumptions of bounded rationality that are constitutive of behavioral economics. Assigned papers often share theoretical foundations in institutional economics and game theory as well as experimental methodologies. Among all clusters in the bibliographic network, papers on economic exchange imply a utilitarian concept of reciprocity in the most consistent way.

\subsection{Cluster 3: Negotiations}

Considering the dispersion of the third cluster (Figure 3), the included papers are surprisingly homogeneous in thematic terms. Almost all publications focus on different forms of negotiations and the main factors by which they are influenced. This line of inquiry thus elucidates reciprocity between negotiators in organizational settings as a specific instance of both social and economic exchange. This common edge notwithstanding, several subthemes that are to some extent distinct emerge within the cluster. A couple of papers provide evidence that the way how negotiations emerge and develop largely depend on the socio-cultural context in which they take place (Adair 2003; Adair and Brett 2005; McGinn and Keros 2002). These studies suggest that the behavioral exercise of reciprocity is contingent on socio-cultural factors (such as norms of communication; Adair 2003) rather than adhering to universalistic rules. This particularly applies to the avoidance and resolution of conflicts in negotiations to which other papers devote attention (Brett, Shapiro, and Lytle 1998; Lytle, Brett, and Shapiro 1999; Taylor and Donald 2003). It is thus not only intriguing to study reciprocity when socio-economic exchange is successful, but also when it fails in the first instance. The liability to failure depends, among many other factors, on the kind of media through which negotiating parties communicate. The role of communication media in negotiations (such as phone, e-mail, instant-messaging) is elucidated by a further subgroup of articles (Friedman and Currall 2003; Johnson and Cooper 2009a, b; Paese, Schreiber, and Taylor 2003). For example, Johnson and Cooper (2009a, b) showed that computer-mediated negotiations result in a weaker concern for reciprocity as compared to personal communication. In a related subtheme of research, scholars examine the impact of emotions and values on negotiations and thus consider factors that are often referred to as 'soft' (Butt, Choi, and Jaeger 2005; Olekalns, Robert, Probst, Smith, and Carnevale 2005; Olekalns and Smith 2003). Assigned papers slightly depart from purely utilitarian conceptions of reciprocity by including factors into the analysis that go beyond the rational pursuit of individual benefit. However, despite the thematic variety under the umbrella of negotiations, the majority of articles included into this cluster largely adopts a substantialist, utilitarian view on reciprocity and provide contingency views on how it unfolds in 
dyadic exchange relationships between negotiators.

\subsection{Cluster 4: Interorganizational Rela- tions}

The last and by far smallest cluster contains four articles. The fact that this cluster is disconnected from the main component of the bibliographic network indicates that assigned papers share the roots of management research on reciprocity to a lesser extent than other publications (Figure 1). Except one paper, which puts emphasis on interpersonal reciprocity in relationship marketing (Pervan, Bove, and Johnson 2009), included studies chiefly focus on interorganizational relations (Johnson and Sohi 2001; Lee, Im, and Taylor 2008) or leverage the concept of relational exchange to the intrafirm level (De Ruyter and Wetzels 2000) in order to identify the driving forces of relationship effectiveness in terms of reciprocity. While these studies implicitly adhere to a utilitarian understanding of reciprocity, Pervan, Bove, and Johnson (2009) explicitly extended quid pro quo concepts and direct attention to motivational dispositions beyond the reach of economic incentives.

\section{Discussion and Implications for Further Research}

\subsection{Reciprocity in Current Management Research}

Building on the various results of our bibliometric analysis, it is clear just how wide the variety of the use of the word "reciprocity" is in scholarly management literature. Uses include interpersonal exchange dyads (Adair 2003), interpersonal exchange rings in work groups (Deckop, Cirka, and Andersson 2003), "exclusive chain swap" between organization and its participants (Purvis and Cropley 2003) and even forms of redistributive exchange in the welfare state (Fischer, Irlenbusch, and Sadrieh 2004). With regard to the motivational dimension of reciprocity, it can be concluded that all extracted clusters tend to be dominated by a desocialized, utility-oriented take on reciprocity. Exemplary publications are those centering on the constellation of dyadic exchange, especially individual strategies and motives of action (e.g., Adair 2003; Coyle-Shapiro 2002). One repeatedly also encounters an expanded concept of reciprocity (e.g., Flynn 2006; Cox 2004; Koster and Sanders 2006; Hayashi, Ostrom, Walker, and
Yamagishi 1999; Nowak and Sigmund 2005). In these papers, either complex exchange constellations are the subject of analysis (e.g., Cox 2004; Nowak and Sigmund 2005) or the exchange process is seen as being affected by multiple social variables such as media (Johnson and Cooper 2009b), social relations (Koster and Sanders 2006), language (Flynn 2006), and national culture (Hayashi Ostrom, Walker, and Yamagishi 1999). This common interest in an extension of the traditional quidpro-quo interpretation of exchange implies ambivalence in the current understanding of reciprocity. On the one hand, the authors of most of the articles that we examined for this study more or less explicitly pointed to the calculating, instrumental character of reciprocity. On the other hand, the mentioned sociocultural variables play an important role in the various conceptions of reciprocity, offsetting the main understanding of reciprocity as an interaction based on economic calculations of utility. Although one usually finds only implicit references to the idea that processes of reciprocal interaction rest on a relatively broad set of motives, some articles do become quite specific. In keeping with Gouldner, for instance, Deckop, Cirka, and Andersson (2003) stated that "reciprocity has developed in human societies as a moral norm that transcends egoistic motivation" (p. 103).

In the ontological dimension, most articles subscribed to the idea that reciprocity stems from the maximization of benefit have, additionally, an underlying model of action with an inherent order of preferences in common. All these contributions, whether in psychology, social psychology, or economics based on game theory, the conceptualizations of reciprocity start from a predisposed interactional model. In essence, this fixed position means that the actors, deep down, do not deviate from their order of preferences and that a mutual give and take is not possible between them. The great majority of them thus follow a substantialist ontology, although reciprocity as a social phenomenon is about a fundamentally relational concept in which the discrete actors (persons, groups, and organizations) are supposed to be the crux of analysis. In accordance with the predominant substantialist paradigm, actors see interaction media (e.g., messenger systems, e-mail, telephone) or socio-cultural environments (norms, symbol systems) as independent variables that restrict the decision-making scope for homo oeconomicus. It is more than forty 
years ago that the anthropologist Levi-Strauss (1969) stated in his observations on reciprocal exchange relationships that "an exchange is about much more than the things that are exchanged" (p. 116). This "more" in exchange processes is, however, from the substantialist viewpoint, "marginalised in favour of a monocausal explanation of the exchange" (Hillebrandt 2008: 11, translated by the authors). There is a faint glimmer of the sociocultural complexity of the reciprocal interaction processes in one paper (Westwood, Sparrow, and Leung 2001), but its relational character is never the focus of the research. Only a few articles are informed by a relational ontology (one of these exceptions is McGinn and Keros 2002). Combining the motivational and the ontological dimension, the vast bulk of management research on reciprocity is located in the benefit-oriented substantialist quadrant of our classification system (Figure 4).

\subsection{Implications for Future Management Research}

The predominance of benefit-oriented, substantialist research on reciprocity raises the question if, and how, an alternative (i.e., moral-oriented, relationalist) view can contribute to management studies. For example, Weber and Göbel (2010), in their work on reciprocity in the venture capital business, showed that each exchange party's motive to take action is causally aligned along processes of mutual recognition, attribution, and interpretation. Given such conceptions of interaction processes, actors adopt the perspective of the "generalized other" (Mead 1934) before actually making personal choices. To explore this phenomenon in greater depth, it seems that a theoretical perspective would be fruitful, which abandons the traditional dualism between "subject" and "object", "action" and "structure" or "body" and "mind" in favor of a praxeological because it is relational - understanding of reciprocal interaction processes, and which considers in this context the action motivation as a changing variable (i.e. not as a constant). Following Reckwitz (2003) reciprocal action means, from a praxeological viewpoint,

"that action also contains elements of intentionality - as the paradigm of homo oeconomicus emphasizes -, that it may also effortlessly accommodate normative criteria - as homo sociologicus elucidates -, that there is no doubt that symbolic sche- mas are employed in it - as the other branches of culturalism point out -, that the statuses of intentionality, normativity and schemas are fundamentally changed if we assume that action in terms of practices can be understood first and foremost as knowledge-based activity, as activities in which a practical knowledge, a capability in terms of knowhow and practical understanding, is utilized." (p. 291-292, translated by the authors).

Thus every exchange practice and every constellation of exchange practices - from support in the workplace (Flynn 2006) to structuring of interorganizational exchange relationships (Johnson and Sohi 2001), from negotiating by parties in a conflict (Taylor and Donald 2003) to the options of intergenerational resources maintenance (Fischer, Irlenbusch, and Sadrieh 2004) - calls for very specific forms of a practical knowledge and pre-requires these forms from those actors who exert them. In addition, a practice, as a complex of knowledgedependent behavioral routines, "also [pre-requires] very specific artefacts", which must exist, if a practice is to emerge and is thus to come to fruition and be reproduced" (Reckwitz 2003: 291, translated by the authors). There was repeated evidence in the papers analyzed, for example, of utilization of communication media (such as instant messaging) as being constitutive for the genesis of this kind of exchange practices. So, while the emphasis of behavioral routines for the persistence of social practices suggests a rather static theory of social practices, the relevance of new artefacts such as communication media or norm systems indicates the changeability of social exchange practices.

Assuming that it is appropriate to consider exchange as a social practice form, the single practices - give, take, reciprocate and take again - that constitute an exchange must succeed each other - in order for the exchange to be carried to completion (Hillebrandt 2008: 2). This succession of single practices indicates evaluation as a key feature for the practice theory of exchange (Hillebrandt 2008: 4). It is only through cultural symbolizations that objects can be conceived as objects worthy of exchange. So, whether an object is seen by the actors as a gift, goods, remuneration for work rendered, a bribe, tax, etc. depends significantly on the symbolic context in which the exchange practice is exerted. The necessary cultural schemas and symbolic forms are seen by actors in this reading as habitually 
Figure 4: Current management research on reciprocity

\section{Benefit}

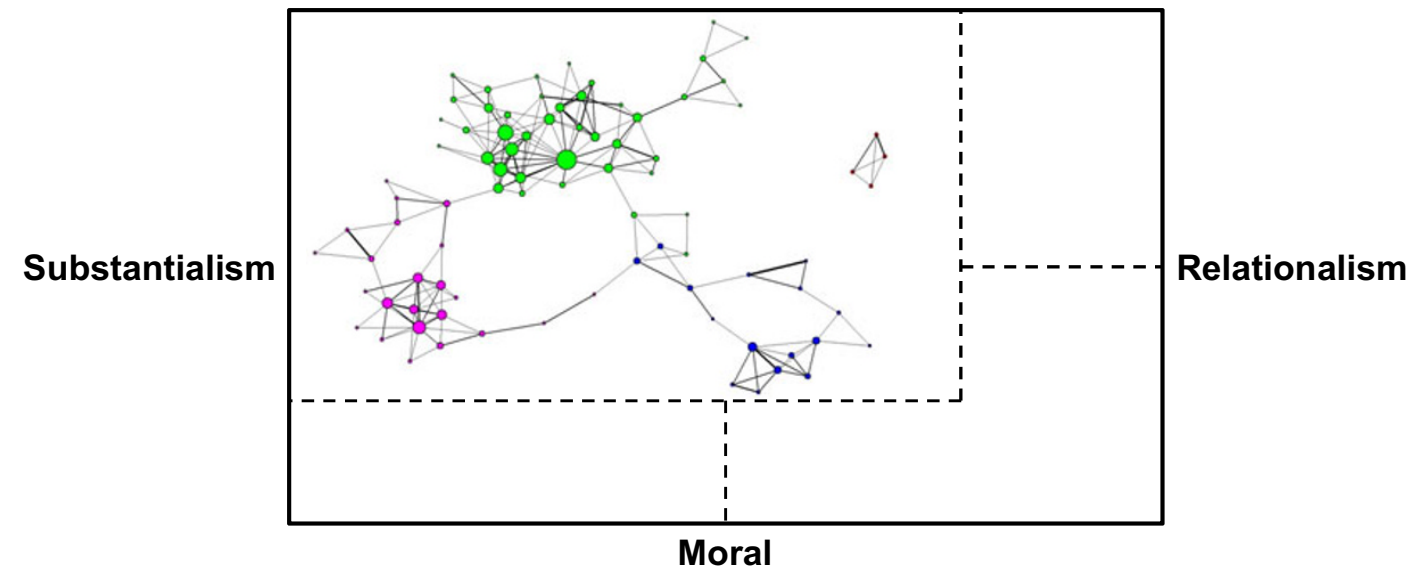

anchored, indicatory patterns that are incorporated and updated in the relevant single practices. With respect to the difference to other practice forms of action coordination (such as, for example, directive orders or programs) every exchange must be considered against the background of cultural evaluations, which are or become objectified to the matterrelated, social and time-based dimension as symbolic forms of reciprocity" (Hillebrandt 2008: 12, translated by the authors). Thus, with regard to a discrete market purchase (e.g., e-commerce, stocks and shares transaction, car purchase) the concrete value of the exchange object is at the center of the exchange practice. The reciprocal relationship between the exchange partners - and therefore the social dimension - is principally invalid when a purchase agreement arises and there is no reason to perpetuate the reciprocal relationship. It is quite a different matter with regard to LMX (Sparrowe and Liden 1997). In order to analyze in the context of this leadership relations the form of inter-linking of exchange practices to exchange forms, in addition to the concrete "thing" or matter-related dimension, the symbols should be taken into account which emerge from the social dimension of the exchange practice. It is only by taking into account the symbols that the nature of the exchange situation becomes clear. It therefore makes a difference whether leader and member meet each other to engage in an expert discourse, to issue or be given a directive order, or to conduct MBO talks. In other words, these two symbolic forms of reciprocity, the concrete and symbol level, which are focused on which superior exchanges what, with which employee, are constitutive for completion of the exchange practice in the context of LMX.

If we extend our field of view to include the "exclusive chain swap", as is typical, for example, of psychological contract relationships (Westwood, Sparrow, and Leung 2001), or to include the redistributive exchange, which is constitutive for the abstract exchange arrangement of the welfare state (Fischer, Irlenbusch, and Sadrieh 2004) a wide variety of possible exchange forms becomes visible in each specific combination of matter-related and social dimensions. This complex picture of the various different exchange forms is rendered sharper and more precise by integrating the time dimension in the analysis of the exchange practice to the extent, "as the time-based treatment of the topic practice forms exemplifies and demonstrates the process characteristics of the exchange" (Hillebrandt 2008: 16 , translated by the authors). For example, if in a stocks and shares transaction, as a strictly matterrelated exchange in sale and purchase of company shares, the exchange practices are executed in a synchronized manner, the practices, of give, take and reciprocate are symbolized as discrete events in the time dimensions past and future. This applies, for instance, to the context of LMX (Sparrowe and Liden 1997), coworker behavior (Koster and Sanders 2006) or company networks (De Ruyter and Wetzels 2000). With respect to a specific interweavement of matter-related, social and time-based symbols, numerous practice forms of exchange can emerge.

In contrast to this conceptual variety in the relationalist view, in the substantialist view there are only 
two exchange forms: exchange, which can be derived from purpose-rational calculation of the actors participating (Blau 1964; Coleman 1990), and exchange, which stems from a superordinated norm of reciprocity (Gouldner 1960). Therefore, if future investigations not only focused more intensively on various different action motivations in the context of a relationalist approach, but also took into account practice-theoretical considerations when considering the often highly complex exchange forms and practices, researchers would significantly advance and develop management theories. For example, a field of application that would benefit from a relationalist view on reciprocity is social network research. This holds due to both its relationalist moral-orientation and its integration of practice. In the tradition of social network research, the question of the actual motives of action, the motivation of the norms of reciprocity, as treated by Coleman (1990), for instance, in closed and cohesive networks, is not investigated, or only investigated implicitly and superficially. As a result, "blind spots" emerge in this theory with regard to the motives of action possessed by the relevant actors; these blind spots could be "illuminated" by means of a development and advancement of the moral-oriented perspective on reciprocity. Furthermore, the integration of time and therewith network dynamics, i.e. longitudinal studies, are rare, as social network research is currently dominated by static investigations of structural features of networks at a certain moment in time. By integrating the theory of practice - and with it the additional dimensions of time, sociality and content - into social network research, our current understanding of social networks would be deepened. In addition, social network research is in its infancy with respect to the negative effects of social networks, i.e. what is known as social liability (Labianca and Brass 2006; Weber and Weber 2011). It is particularly in this field, in which, contrary to expectations, reciprocity does not occur, social capital is either non-existent or even reverses in the opposite, negative direction, that a moral-oriented, relationalist perspective could provide new findings. Further, integrating the various dimensions of such a perspective would enable a clearer picture, on the one hand, of how and why knots and ties relate to one another and, on the other, the processes and resources flows between these knots. It would be particularly valuable with regard to explaining the dynamics, which means how these motivations may change over time and, with these changes, the effects on inter-relating resource flows between knots, as well as the back coupling on structures. For this type of analysis, Hillebrandt (2008) suggested a qualitative research approach.

\subsection{Limitations}

Although our bibliometric methodology has provided a systematic approach to the reviewed literature, it is subject to some limitations. The creation of the bibliographic network was preceded by a rigorous reduction of the initial data both by search criteria during data retrieval and by thresholds in the subsequent analysis. The answer to the question of which clusters are extracted and which remain invisible because they are not as prevalent in the data thus partly depends on technical decisions we have made. Further limitations of our study arise from particularities of applying the method of bibliographic coupling. One shortcoming of this technique is that publications with comparatively long reference lists are over weighted. The more entries a bibliography contains, the more likely it is to have intersections with reference lists of other publications. Articles written by authors who cite extensively tend to have a higher network centrality than those with shorter bibliographies. Another drawback is that the length of a reference list may depend not only on author preferences but also on journal standards. More important, bibliographic coupling measures activity rather than impact. Our ranking of classic research on the reciprocity concept in various social sciences accounts for impact in terms of citations, but the documents in the bibliographic network of management research are mapped regardless of the recognition they have received from the scholarly community. In this part of the analysis, then, we may have detected peripheral subfields of research that have hitherto attracted only limited attention. Nonetheless, researchers seeking orientation in the field in order to set their own research agenda may be better served by this combination of references to current trends and past traditions than by reliance on the latter alone.

\section{Conclusion}

Our goal in this paper was to provide a review of the reciprocity research in the field of management and beyond and to explore the different streams of research that have emerged on the subject in the fields 
of economics, psychology, sociology, anthropology, and management predominantly since the early 1900s. In order to detect these current patterns of research and to improve the understanding of potential similarities and differences in theoretical and conceptual accounts of reciprocity, we applied a bibliometric methodology to this immense body of literature. The methodology was chosen because it is particularly useful when applied to large numbers of publications whose interrelations are hard to determine from the inevitably limited view that can be offered by scholars. To address this reality, we believe we made several theoretical contributions: First, we provided a comprehensive overview of the management research on reciprocity and have pointed out its various disciplinary origins in the social sciences. Keeping in mind an ontological and a motivational dimension that crystallized from this detailed review, we developed a classification system for categorizing the classic research publications on reciprocity. In a subsequent bibliometric analysis encompassing 232 documents and more than 12,000 citations, we identified seven distinct, yet interrelated, clusters of reciprocity research whose underlying understanding of reciprocity are described in this paper. Aided by our two dimensions for categorization, the motivational as well as the ontological, we showed that these subsidiary fields of research, though varying considerably in theoretical and methodological terms, have underlying concepts of reciprocity that are comparatively homogeneous across the extracted clusters.

The strong link between the different clusters in this body of management research is a utility-oriented understanding of reciprocity. Despite its dominance, there are perceptible nods to a kind of reciprocity oriented to morality, especially in the cluster of articles on negotiations. The basic position of research on reciprocity is permeated by substantialist ontology, whose proponents view the elements of social orders in isolation and have a static image of them, a perspective that draws their attention away from changes in and relations between those elements. The increasing significance of research on morally oriented reciprocity is paralleled by incipient indications of a relational ontology. On the whole, this development reflects the "cultural turn" observable in the social sciences for some time now. It has now extended to reciprocity research, forming constitutive relations between the social context and reciprocal motives for action. Due to and based on this development, we have suggested the theory of practice as a potentially valuable construct which allows the relational aspect of reciprocity to unfold. By viewing in a practice theory of exchange the aspects of action motivation, social and cultural context, space and time as interwoven, we can identify and see clearly the relational character of reciprocity.

In sum, our analysis offers a discerning identification and classification of the underlying motives and basic ontological positions argued in the hitherto bewildering abundance of management research on reciprocity. We presume that the desocialized, utility-oriented understanding of reciprocity will continue to mark most of the research on the subject. However, theoretical underpinnings for the emergence of a different perspective already exist not only in the works by scholars named in Figure 5 but also in structuration theory (Giddens 1984), systems theory (Luhmann 1995), and complexity theory (Stacey 1995). We therefore also anticipate that the extension of the traditional quid-pro-quo interpretation of exchange will broadly lead to a socioculturally enriched understanding of reciprocity, one that takes the relational perspective into account.

\section{References}

Abbott, Andrew (1988): Transcending General Linear Reality, Sociological Theory, 6 (2): 169-186.

Adair, Wendi L. (2003): Integrative Sequences and Negotiation Outcome in Same- and Mixed-Culture Negotiations, International Journal of Conflict Management, 14 (3-4): 273-296.

Adair, Wendi L. and Jeanne M. Brett (2005): The Negotiation Dance: Time, Culture, and Behavioral Sequences in Negotiation, Organization Science, 16 (1): 33-51.

Adams, John S. (1965): Inequity in Social-Exchange, Advances in Experimental Social Psychology, 2: 267-299.

Ahlgren, Per and Bo Jarneving (2008): Bibliographic Coupling, Common Abstract Stems and Clustering: A Comparison of Two Document-Document Similarity Approaches in the Context of Science Mapping, Scientometrics, 76 (2): 273-290.

Akerlof, George A. (1982): Labor Contracts as Partial Gift Exchange, Quarterly Journal of Economics, 97 (4): 543-569.

Altman, Irwin and Dalmas A. Taylor (1973): Social Penetration: The Development of Interpersonal Relationships, Rinehart: New York, NY et al.

Arrow, Kenneth (1975): Gifts and Exchanges, in: Edmund S. Phelps (ed.): Altruism, Morality, and Economic Theory, Sage: New York, NY, 13-28.

Axelrod, Robert M. (1984): The Evolution of Cooperation, Basic Books: New York, NY.

Axelrod, Robert M. and William D. Hamilton (1981): The Evolution of Cooperation, Science, 211 (4489): 1390-1396. 
Baron, Reuben M. and David A. Kenny (1986): The Moderator Mediator Variable Distinction in Social Psychological Research: Conceptual, Strategic, and Statistical Considerations, Journal of Personality and Social Psychology, 51 (6): 1173-1182.

Berg, Joyce, John Dickhaut, and Kevin McCabe (1995): Trust, Reciprocity, and Social History, Games and Economic Behavior, 10 (1): 122-142.

Bernerth, Jeremy B., Achilles A. Armenakis, Hubert S. Feild, William F. Giles, and H. Jack Walker (2007): Leader-Member Social Exchange (LMSX): Development and Validation of a Scale, Journal of Organizational Behavior, 28 (8): 979-1003.

Bernerth, Jeremy B., Achilles A. Armenakis, William F. Giles, and H. Jack Walker (2008): The Influence of Personality Differences Between Subordinates and Supervisors on Perceptions of LMX: An Empirical Investigation, Group \& Organization Management, 33 (2): 216-240.

Biele, Guido, Rieskamp, Jorg, and Uwe Czienskowski (2008): Explaining Cooperation in Groups: Testing Models of Reciprocity and Learning, Organizational Behavior and Human Decision Processes, 106 (2): 89-105.

Biggart, Nicole W. and Rick Delbridge (2004): Systems of Exchange, Academy of Management Review, 29 (1): 28-49.

Blau, Peter M. (1964): Exchange and Power in Social Life, Wiley: New York, NY et al.

Blau, Peter M. (1974): On the Nature of Organizations, Wiley: New York, NY et al.

Bolton, Gary E., Elena Katok, and Axel Ockenfels (2004): How Effective are Electronic Reputation Mechanisms? An Experimental Investigation, Management Science, 50 (11): 1587-1602.

Bolton, Gary E. and Axel Ockenfels (2000): ERC: A Theory of Equity, Reciprocity, and Competition, American Economic Review, 90 (1): 166-193.

Borgatti, Stephen P., Martin G. Everett, and Linton C. Freeman (2002): Ucinet for Windows: Software for Social Network Analysis, Analytic Technologies: Harvard, MA.

Bosse, Douglas A., Robert A. Phillips, and Jeffrey S. Harrison (2009): Stakeholders, Reciprocity, and Firm Performance, Strategic Management Journal, 30 (4): 447-456.

Bourdieu, Pierre (1990): The Logic of Practice, Stanford University Press: Stanford, CA.

Bourdieu, Pierre (1998): The Practical Reason: On the Theory of Action, Stanford University Press: Stanford, CA.

Bowey, James L. and Geoff Easton (2007): Entrepreneurial Social Capital Unplugged: An Activity-Based Analysis, International Small Business Journal, 25 (3): 273-306.

Boyd, Robert and Peter J. Richerson (1992): Punishment Allows the Evolution of Cooperation (or Anything Else) in Sizable Groups, Ethology and Sociobiology, 13 (3): 171-195.

Brandts, Jordi and Gary Charness (2003): Truth or Consequences: An Experiment, Management Science, 49 (1), 116-130.

Brennan, Ian and Kenneth D. Bahn (1991): Door-In-The-Face, That's-Not-All, and Legitimizing a Paltry Contribution: Reciprocity, Contrast Effect and Social Judgment Theory Explanations, Advances in Consumer Research, 18: 586-590.
Brett, Jeanne M., Debra L. Shapiro, and Anne L. Lytle (1998): Breaking the Bonds of Reciprocity in Negotiations, Academy of Management Journal, 41 (4): 410-424.

Burt, Ronald S. (1992): Structural Holes, Harvard University Press: Cambridge, MA.

Butler, John K. (1991): Toward Understanding and Measuring Conditions of Trust: Evolution of a Conditions of Trust Inventory, Journal of Management, 17 (3): 643-663.

Butt, Arif N., Jin N. Choi, and Alfred M. Jaeger (2005): The Effects of Self-Emotion, Counterpart Emotion, and Counterpart Behavior on Negotiator Behavior: A Comparison of IndividualLevel and Dyad-Level Dynamics, Journal of Organizational Behavior, 26 (6): 681-704.

Cable, Daniel M. and Scott Shane (1997): A Prisoner's Dilemma Approach to Entrepreneur-Venture Capitalist Relationships, Academy of Management Review, 22 (1): 142-176.

Cashdan, Elizabeth A. (1985): Coping With Risk: Reciprocity Among the Basarwa of Northern Botswana, Man, 20 (3): 454474.

Cassirer, Ernst (1953): Substance and Function, Dover: New York, NY.

Chang, Linda, Mandy Cheng, and Ken T. Trotman (2008): The Effect of Framing and Negotiation Partner's Objective on Judgments About Negotiated Transfer Prices, Accounting Organizations and Society, 33 (7-8): 704-717.

Charness, Gary and Matthew Rabin (2002): Understanding Social Preferences With Simple Tests, Quarterly Journal of Economics, 117 (3): 817-869.

Chiu, Chao-Min, Meng-Hsiang Hsu, and Eric T. G. Wang (2006): Understanding Knowledge Sharing in Virtual Communities: An Integration of Social Capital and Social Cognitive Theories, Decision Support Systems, 42 (3): 1872-1888.

Cialdini, Robert B. (1993): Influence: Science and Practice, $3^{\text {rd }}$ ed., Harper Collins: New York, NY.

Coleman, James (1990): Foundations of Social Theory, Harvard University Press: Cambridge, MA.

Cox, James C. (2004): How to Identify Trust and Reciprocity, Games and Economic Behavior, 46 (2): 260-281.

Coyle-Shapiro, Jacqueline A. M., Paula C. Morrow, Ray Richardson, and Stephen R. Dunn (2002): Using Profit Sharing to Enhance Employee Attitudes: A Longitudinal Examination of the Effects on Trust and Commitment, Human Resource Management, 41 (4): 423-439.

Cozby, Paul C. (1973): Self-disclosure: A Literature Review, Psychological Bulletin, 79 (2): 73-91.

Cropanzano, Russell and Marie S. Mitchell (2005): Social Exchange Theory: An Interdisciplinary Review, Journal of Management, 31 (6): 874-900.

Dabos, Guillermo E. and Denise M. Rousseau (2004): Mutuality and Reciprocity in the Psychological Contracts of Employee and Employer, Journal of Applied Psychology, 89 (1): 52-72.

Dana, Jason, Daylian M. Cain, and Robyn M. Dawes (2006): What You Don't Know Won't Hurt Me: Costly (but Quiet) Exit in Dictator Games, Organizational Behavior and Human Decision Processes, 100 (2): 193-201. 
De Boer, Elpine M., Arnold B. Bakker, Jef E. Syroit, and Wilmar B. Schaufeli (2002): Unfairness at Work as a Predictor of Absenteeism, Journal of Organizational Behavior, 23 (2): 181-197.

De Ruyter, Ko and Martin Wetzels (2000): Determinants of a Relational Exchange Orientation in the Marketing-Manufacturing Interface: An Empirical Investigation, Journal of Management Studies, 37 (2): 257-276.

De Solla Price, Derek J. (1965): The Science of Science, in: John R. Platt (ed.): New Views on the Nature of Man, University Press: Chicago, IL et al., 47-70.

De Vos, Ans, Dirk Buyens, and René R. Schalk (2003): Psychological Contract Development During Organizational Socialization: Adaptation to Reality and the Role of Reciprocity, Journal of Organizational Behavior, 24 (5): 537-559.

Deckop, John R., Carol C. Cirka, and Lynne M. Andersson (2003): Doing Unto Others: The Reciprocity of Helping Behavior in Organizations, Journal of Business Ethics, 47 (2): 101-113.

Deluga, Ronald J. (1998): Leader-Member Exchange Quality and Effectiveness Ratings: The Role of Subordinate-Supervisor Conscientiousness Similarity, Group \& Organization Management, 23 (2): 189-216

Desiraju, Ramarao and David E. M. Sappington (2007): Equity and Adverse Selection, Journal of Economics \& Management Strategy, 16 (2): 285-318.

Dewey, John and Arthur F. Bentley (1949): Knowing and the Known, Beacon Press: Boston, MA

Dorado, Miguel A., Francisco J. Medina, Lourdes Munduate, Inmaculada F. J. Cisneros, and Martin Euwema (2002): Computer-Mediated Negotiation of an Escalated Conflict, Small Group Research, 33 (5): 509-524.

Dufwenberg, Martin and Georg Kirchsteiger (2004): A Theory of Sequential Reciprocity, Games and Economic Behavior, 47 (2): 268-298.

Dulac, Tanguy, Jaqueline A. M. Coyle-Shapiro, David J. Henderson, and Sandy J. Wayne (2008): Not All Responses to Breach are the Same: The Interconnection of Social Exchange and Psychological Contract Processes in Organizations, Academy of Management Journal, 51 (6): 1079-1098.

Eder, Paul and Robert Eisenberger (2008): Perceived Organizational Support: Reducing the Negative Influence of Coworker Withdrawal Behavior, Journal of Management, 34 (1): 55-68.

Eisenberger, Robert, Robin Huntington, Steven Hutchison, and Debora Sowa (1986): Perceived Organizational Support, Journal of Applied Psychology, 71 (3): 500-507.

Ekeh, Peter P. (1974): Social Exchange Theory: The Two Traditions, Heinemann: London et al.

Emirbayer, Mustafa (1997): Manifesto for a Relational Sociology, American Journal of Sociology, 103 (2): 281-317.

Evans, W. Randy and Walter D. Davis (2005): High-Performance Work Systems and Organizational Performance: The Mediating Role of Internal Social Structure, Journal of Management, 31 (5): 758-775.

Farh, Jiingh-Lih, Rick D. Hackett, and Jian Liang (2007): Individual-Level Cultural Values as Moderators of Perceived Organizational Support-Employee Outcome Relationships in China: Comparing the Effects of Power Distance and Traditionality, Academy of Management Journal, 50 (3): 715-729.
Fehr, Ernst and Urs Fischbacher (2003): The Nature of Human Altruism, Nature, 425: 785-791.

Fehr, Ernst and Urs Fischbacher (2005): Human Altruism Proximate Patterns and Evolutionary Origins: Analyse \& Kritik, 27 (1): 6-47.

Fehr, Ernst, Urs Fischbacher, and Simon Gächter (2002): Strong Reciprocity, Human Cooperation and the Enforcement of Social Norms, Human Nature, 13 (1): 1-25.

Fehr, Ernst and Simon Gächter (2000): Fairness and Retaliation: The Economics of Reciprocity, Journal of Economic Perspectives, 14 (3): 159-181.

Fehr, Ernst, Georg Kirchsteiger, and Arno Riedl (1993): Does Fairness Prevent Market Clearing? An Experimental Investigation, Quarterly Journal of Economics, 108 (2): 437-459.

Fehr, Ernst, Simon Gächter, and Georg Kirchsteiger (1997): Reciprocity as a Contract Enforcement Device: Experimental Evidence, Econometrica, 65 (4): 833-860.

Fehr, Ernst and Klaus M. Schmidt (1999): A Theory of Fairness, Competition, and Cooperation, Quarterly Journal of Economics, 114 (3): 817-868.

Fennis, Bob M., Loes Janssen, and Kathleen D. Vohs (2009): Acts of Benevolence: A Limited-Resource Account of Compliance With Charitable Requests, Journal of Consumer Research, 35 (6): 906924 .

Ferrin, Donald L., Michelle C. Bligh, and Jeffrey C. Kohles (2008): It Takes Two to Tango: An Interdependence Analysis of the Spiraling of Perceived Trustworthiness and Cooperation in Interpersonal and Intergroup Relationships, Organizational Behavior and Human Decision Processes, 107 (2): 161-178.

Fichman, Mark (2003): Straining Towards Trust: Some Constraints on Studying Trust in Organizations, Journal of Organizational Behavior, 24 (2): 133-157.

Fischer, Maria-Elisabeth, Bernd Irlenbusch, and Abdolkarim Sadrieh (2004): An Intergenerational Common Pool Resource Experiment, Journal of Environmental Economics and Management, 48 (2): 811-836.

Flynn, Francis J. (2006): "How Much Is It Worth to You? Subjective Evaluations of Help in Organizations", Research in Organizational Behavior, 27: 133-174.

Frenkel, Stephen J. and Karin Sanders (2007): Explaining Variations in Co-Worker Assistance in Organizations, Organization Studies, 28 (6): 797-823.

Friedman, Raymond A. and Steven C. Currall (2003): Conflict Escalation: Dispute Exacerbating Elements of E-Mail Communication, Human Relations, 56 (11): 1325-1347.

Garfield, Eugene (1955): Citation Indexes for Science: A New Dimension in Documentation Through Association of Ideas, Science, 122 (3159): 108-111.

Garner, Randy (2005): Post-It Note Persuasion: A Sticky Influence, Journal of Consumer Psychology, 15 (3): 230-237.

Giddens, Anthony (1984): The Constitution of Society: Outline of the Theory of Structuration, University Press: Berkeley, CA.

Göbel, Markus, Günther Ortmann, and Christiana Weber (2007): Reziprozität: Kooperation zwischen Nutzen und Pflicht, $M a-$ nagementforschung, 17: 161-205. 
Gould-Williams, Julian and Fiona Davies (2005): Using Social Exchange Theory to Predict the Effects of HRM Practice on Employee Outcomes: An Analysis of Public Sector Workers, Public Management Review, 7 (1): 1-24

Gouldner, Alvin W. (1960): The Norm of Reciprocity: A Preliminary Statement, American Sociological Review, 25 (2): 161-178.

Granovetter, Mark (1973): Strength of Weak Ties, American Journal of Sociology, 78 (6): 1360-1380.

Granovetter, Mark (1985): Economic Action and Social Structure: The Problem of Embeddedness, American Journal of Sociology, 91 (3): 481-510.

Güth, Werner (1995): On Ultimatum Bargaining Experiments: A Personal Review, Journal of Economic Behavior and Organization, 27 (3): 329-344.

Haar, Jarrod M. (2006): Challenge and Hindrance Stressors in New Zealand: Exploring Social Exchange Theory Outcomes, International Journal of Human Resource Management, 17 (11): 1942-1950.

Hamilton, William D. (1964): The Genetical Evolution of Social behavior. I, Journal of Theoretical Biology, 7 (1): 1-16.

Hannan, R. Lynn (2005): The Combined Effect of Wages and Firm Profit on Employee Effort, Accounting Review, 80 (1): 167188.

Hatfield, Richard C., Christopher P. Agoglia, and Maria H. Sanchez (2008): Client Characteristics and the Negotiation Tactics of Auditors: Implications for Financial Reporting, Journal of Accounting Research, 46 (5): 1183-1207.

Hawkes, Kristen (1993): Why Hunter-Gatherers Work: An Ancient Version of the Problem of Public Goods, Current Anthropology, 34 (4): 341-361.

Hayashi, Nahoko, Elinor Ostrom, James Walker, and Toshio Yamagishi (1999): Reciprocity, Trust, and the Sense of Control: A Cross-Societal Study, Rationality and Society, 11 (1): 27-46.

Hekman, David R., Gregory A. Bigley, H. Kevin Steensma, and James F. Hereford (2009): Combined Effects of Organizational and Professional Identification on the Reciprocity Dynamic for Professional Employees, Academy of Management Jourmal, 52 (3): 506-526

Hillebrandt, Frank (2008): Der Tausch als marktstrukturierende Praxisform. Ein Beitrag zur kultursoziologischen Fundierung der Wirtschaftssoziologie, http://www.mpifg.de/wirtschaftssoziologie-0802/papers/Hillebrandt.pdf (Access date: 2013-02-19).

Hirsch, Paul M. and Michael Lounsbury (1997): Ending the Family Quarrel: Toward a Reconciliation of 'Old' and 'New' Institutionalisms, American Behavioral Scientist, 40 (4): 406-418.

Hirshleifer, David (1988): Cooperation in a finitely repeated prisoner's dilemma game with ostracism, Working Paper, University of California: Los Angeles, CA.

Ho, Violet T., Denise M. Rousseau, and Laurie L. Levesque (2006): Social Networks and the Psychological Contract: Structural Holes, Cohesive Ties, and Beliefs Regarding Employer Obligations, Human Relations, 59 (4): 459-481.

Homans, George C. (1961): Social Behavior: Its Elementary Forms, Harcourt, Brace \& World: New York, NY.

Jarneving, Bo (2005): A Comparison of Two Bibliometric Methods for Mapping of the Research Front, Scientometrics, 65 (2): 245-263.
Jarneving, Bo (2007): Bibliographic Coupling and Its Application to Research-Front and Other Core Documents, Journal of Informetrics, 1 (4): 287-307.

Johnson, Jean L. and Ravipreet S. Sohi (2001): The Influence of Firm Predispositions on Interfirm Relationship Formation in Business Markets, International Journal of Research in Marketing, 18 (4): 299-318.

Johnson, Norman A. and Randolph B. Cooper (2009a): Media, Affect, Concession, and Agreement in Negotiation: IM Versus Telephone, Decision Support Systems, 46 (3): 673-684.

Johnson, Norman A. and Randolph B. Cooper (2009b): Power and Concession in Computer-Mediated Negotiations: An Examination of First Offers, MIS Quarterly, 33 (1): 147-170.

Kacmar, K. Michele, Martha C. Andrews, David L. Van Rooy, R. Chris Steilberg, and Stephen Cerrone (2006): Sure Everyone Can Be Replaced ... But at What Cost? Turnover as a Predictor of UnitLevel Performance, Academy of Management Journal, 49 (1): 133-144.

Kaplan, Hillard and Kim Hill (1985): Hunting Ability and Reproductive Success Among Male Ache Foragers: Preliminary Results, Current Anthropology, 26 (1): 131-133.

Kessler, Maxwell Mirton (1963): Bibliographic Coupling Between Scientific Papers, American Documentation, 14 (1): 10-25.

Kollock, Peter (1994): The Emergence of Exchange Structures: An Experimental Study of Uncertainty, Commitment, and Trust, American Journal of Sociology, 100 (2): 313-345.

Kolm, Serge-Christophe (2008): Reciprocity: An Economics of Social Relations, University Press: Cambridge, UK et al.

Koster, Ferry and Karin Sanders (2006): Organisational Citizens or Reciprocal Relationships? An Empirical Comparison, Personnel Review, 35 (5): 519-537.

Kreps, David M., Paul Milgrom, John Roberts, and Robert Wilson (1982): Rational Cooperation in the Finitely Repeated Prisoners' Dilemma, Journal of Economic Theory, 27 (2): 245-252.

Lado, Augustine A., Nancy G. Boyd, and Susan C. Hanlon (1997): Competition, Cooperation, and the Search for Economic Rents: A Syncretic Model, Academy of Management Review, 22 (1): 110141.

Larson, Andrea (1992): Network Dyads in Entrepreneurial Settings: A Study of the Governance of Exchange Relationships, Administrative Science Quarterly, 37 (1): 76-104.

Lee, Doo-Hee, Seunghee Im, and Charles R. Taylor (2008): Voluntary Self-Disclosure of Information on the Internet: A Multimethod Study of the Motivations and Consequences of Disclosing Information on Blogs, Psychology \& Marketing, 25 (7): 692-710.

Lester, Scott W., Bruce M. Meglino, and M. Audrey Korsgaard (2008): The Role of Other Orientation in Organizational Citizenship Behavior, Journal of Organizational Behavior, 29 (6): 829841.

Levi-Strauss, Claude (1969): The Elementary Structures of Kinship, Beacon Press: Boston, MA.

Leydesdorff, Loet (2001): The Challenge of Scientometrics: The Development, Measurement, and Self-Organization of Scientific Communications, Universal Publishers: Parkland, IL.

Liden, Robert C., Sandy J. Wayne, Maria L. Kraimer, and Raymond T. Sparrowe (2003): The Dual Commitments of Contingent Workers: An Examination of Contingents' Commitment to the 
Agency and the Organization, Journal of Organizational Behavior, 24 (5): 609-625.

Loch, Christoph H. and Yaozhong Wu (2008): Social Preferences and Supply Chain Performance: An Experimental Study, Management Science, 54 (11): 1835-1849.

Luhmann, Niklas (1995): Social Systems, Stanford University Press: Stanford, CA.

Lytle, Anne L., Jeanne M. Brett, and Debra L. Shapiro (1999): The Strategic Use of Interests, Rights, and Power to Resolve Disputes, Negotiation Journal, 15 (1): 31-52.

Malhotra, Deepak (2004): Trust and Reciprocity Decisions: The Differing Perspectives of Trustors and Trusted Parties, Organizational Behavior and Human Decision Processes, 94 (2): 61-73

Malinowski, Bronislaw (1949): Crime and Custom in Savage Society, Routledge: London.

Mathwick, Charla, Caroline Wiertz, and Ko De Ruyter (2008): Social Capital Production in a Virtual P3 Community, Journal of Consumer Research, 34 (6): 832-849.

Mauss, Marcel (1990): The Gift: The Form and Reason for Exchange in Archaic Societies, Norton: New York, NY et al.

McGinn, Kathleen L. and Angela T. Keros (2002): Improvisation and the Logic of Exchange in Socially Embedded Transactions, Administrative Science Quarterly, 47 (3): 442-473.

Mead, George H. (1934): Mind, Self, and Society, University of Chicago Press: Chicago, IL.

Meeker, Barbara F. (1984): Cooperative Orientation, Trust, and Reciprocity, Human Relations, 37 (3): 225-243.

Merton, Robert (1957): Social Theory and Social Structure, Free Press: Glencoe, IL.

Molm, Linda D. (2003): Theoretical Comparisons of Forms of Exchange, Sociological Theory, 21 (1): 1-17.

Morales, Andrea C. (2005): Giving Firms an "E" for Effort: Consumer Responses to High-Effort Firms, Journal of Consumer Research, 31 (4): 806-812.

Muse, Lori, Stanley G. Harris, William F. Giles, and Hubert S. Field (2008): Work-Life Benefits and Positive Organizational Behavior: Is There a Connection?, Journal of Organizational Behavior, 29 (2): 171-192.

Muthusamy, Senthil K. and Margaret A. White (2005): Learning and Knowledge Transfer in Strategic Alliances: A social Exchange View, Organization Studies, 26 (3): 415-441.

Nalebuff, Barry J. and Adam Brandenburger (1998): Co-Opetition, Doubleday: New York, NY et al.

Nowak, Martin A. and Karl Sigmund (2005): Evolution of Indirect Reciprocity, Nature, 437: 1291-1298.

Olekalns, Mara, Christopher Robert, Tahira Probst, Philip L. Smith, and Peter J. Carnevale (2005): The Impact of Message Frame on Negotiators' Impressions, Emotions, and Behaviors, International Journal of Conflict Management, 16 (4): 379-402.

Olekalns, Mara and Philip L. Smith (2003): Social Motives in Negotiation: The Relationships Between Dyad Composition, Negotiation Processes and Outcomes, International Journal of Conflict Management, 14 (3-4): 233-254.

Paese, Paul W., Ann M. Schreiber, and Adam W. Taylor (2003): Caught Telling the Truth: Effects of Honesty and Communication
Media in Distributive Negotiations, Group Decision and Negotiation, 12 (6): 537-566.

Parkhe, Arvind (1993): Strategic Alliance Structuring: A Game Theoretic and Transaction Cost Examination of Interfirm Cooperation, Academy of Management Journal, 36 (4): 794-829.

Parzefall, Marjo-Ritta (2008): Psychological Contracts and Reciprocity: A Study in a Finnish Context, International Journal of Human Resource Management, 19 (9): 1703.1719.

Pervan, Simon J., Liliana L. Bove, and Lester W. Johnson (2009): Reciprocity as a Key Stabilizing Norm of Interpersonal Marketing Relationships: Scale Development and Validation, Industrial Marketing Management, 38 (1): 60-70.

Pizzorno, Alessandro (1991): On the Individualistic Theory of Social Order, in: Pierre Bourdieu and James S. Coleman (eds.): Social Theory for a Changing Society, Sage: New York, NY, 209231.

Polanyi, Karl (1944): The Great Transformation: The Political and Economic Origins of Our Time, Rinehart: New York, NY.

Powell, Walter W. (1987): Hybrid Organizational Arrangements: New Form or Transitional Development?, California Management Review, 30 (1): 67-87.

Price, Michael E. (2006a): Judgments About Cooperators and Freeriders on a Shuar Work Team: An Evolutionary Psychological Perspective, Organizational Behavior and Human Decision Processes, 101 (1): 20-35.

Price, Michael E. (2006b): Monitoring, Reputation, and 'Greenbeard' Reciprocity in a Shuar Work Team, Journal of Organizational Behavior, 27 (2): 201-219.

Pritchard, Alan (1969): Statistical Bibliography or Bibliometrics, Journal of Documentation, 25 (4): 348-349.

Purvis, Lynne J. Millward and Mark Cropley (2003): Psychological Contracting: Processes of Contract Formation During Interviews Between Nannies and Their 'Employers', Journal of Occupational and Organizational Psychology, 76 (2): 213-241.

Rabin, Matthew (1993): Incorporating Fairness Into Game Theory and Economics, American Economic Review, 83 (5): 1281-1302.

Reckwitz, Andreas (2003): Grundelemente einer Theorie sozialer Praktiken: Eine sozialtheoretische Perspektive, Zeitschrift für Soziologie, 32 (4): 282-301.

Robinson, Sandra L. and Elizabeth W. Morrison (1995): Psychological Contracts and OCB: The Effect of Unfulfilled Obligations on Civic Virtue Behaviour, Journal of Organizational Behavior, 16 (3): $289-298$.

Roth, Alvin E. (1995): Bargaining Experiments, in: John H. Kagel and Alvin E. Roth (eds.): Handbook of experimental economics, Princeton University Press: Princeton, NJ, 253-348.

Sahlins, Marshall D. (1972): Stone Age Economics, Gruyter: New York, NY.

Salamon, Sabrina D. and Yuval Deutsch (2006): OCB as a Handicap: An Evolutionary Psychological Perspective, Journal of Organizational Behavior, 27 (2): 185-199.

Sanders, Karin and Birgit Schyns (2006): Trust, Conflict and Cooperative Behavior: Considering Reciprocity Within Organizations, Personnel Review, 35 (5): 508-518.

Settoon, Randall P., Nathan Bennett, and Robert C. Liden (1996): Social Exchange in Organizations: Perceived Organizational 
Support, Leader-Member Exchange, and Employee Reciprocity, Journal of Applied Psychology, 81 (3): 219-227.

Simmel, Georg (1950): The Sociology of Georg Simmel, Free Press: Glencoe, IL.

Sloof, Randolph, Hessel Oosterbeek, and Joep Sonnemans (2007): Does Making Specific Investments Unobservable Boost Investment Incentives?, Journal of Economics \& Management Strategy, 16 (4): 911-942.

Smith, Adam (1776/1976): An Inquiry Into the Nature and Causes of the Wealth of Nations. University of Chicago Press: Chicago, IL.

Song, Fei (2009): Intergroup Trust and Reciprocity in Strategic Interactions: Effects of Group Decision-Making Mechanisms, Organizational Behavior and Human Decision Processes, 108 (1): 164-173.

Sparrowe, Raymond T. and Robert C. Liden (1997): Process and Structure in Leader-Member Exchange, Academy of Management Review, 22 (2): 522-552.

Taylor, Paul J. and Ian Donald (2003): Foundations and Evidence for an Interaction-Based Approach to Conflict Negotiation, International Journal of Conflict Management, 14 (3-4): 213-232.

Thibaut, John W. and Harold H. Kelley (1959): The Social Psychology of Groups, Wiley: New York, NY et al.

Trivers, Robert L. (1971): Evolution of Reciprocal Altruism, Quarterly Review of Biology, 46 (1): 35-57.

Verbeke, Willem and Stefan Wuyts (2007): Moving in Social Circles: Social Circle Membership and Performance Implications, Journal of Organizational Behavior, 28 (4): 357-379.

Von Hippel, Eric (1987): Cooperation Between Rivals: Informal Know-How Trading, Research Policy, 16 (6): 291-302.

Wasko, Molly M. and Samer Faraj (2005): Why Should I Share? Examining Social Capital and Knowledge Contribution in Electronic Networks of Practice, MIS Quarterly, 29 (1): 35-57.

Weber, Christiana and Markus Göbel (2010): Reciprocity and Interorganizational Governance: A Multicase Analysis of Exchange Systems, Scandinavian Journal of Management, 26 (2): 134-150.

Weber, Christiana, Günther Ortmann, and Markus Göbel (2010): Reciprocity in and Between Organizations: Cooperation Between Benefit and Obligation, Working Paper, University of Siegen.

Weber, Christiana and Barbara Weber (2011): Exploring the Antecedents of Social Liabilities in CVC Triads: A Dynamic Social Network Perspective, Journal of Business Venturing, 26 (2): 255272.

Weber, J. Mark, Deepak Malhotra, and J. Keith Murnighan (2005): Normal Acts of Irrational Trust: Motivated Attributions and the Trust Development Process, Research in Organizational Behavior, 26: 75-101.

Westwood, Robert, Paul Sparrow, and Alicia Leung (2001): Challenges to the Psychological Contract in Hong Kong, International Journal of Human Resource Management, 12 (4): 621-651.
Wiertz, Caroline and Ko de Ruyter (2007): Beyond the Call of Duty: Why Customers Contribute to Firm-Hosted Commercial Online Communities, Organization Studies, 28 (3): 347-376.

Williamson, Michael G. (2008): The Effects of Expanding Employee Decision Making on Contributions to Firm Value in an Informal Reward Environment, Contemporary Accounting Research, 25 (4): 1183-1209.

Williamson, Oliver E. (1993): Calculativeness, Trust and Economic Organization, Journal of Law \& Economics, 36: 453-486.

Wu, Yaozhong Z., Christoph H. Loch, and Ludo van der Heyden (2008): A Model of Fair Process and its Limits, Manufacturing \& Service Operations Management, 10 (4): 637-653.

Zhang, Ann Y., Anne S. Tsui, Lynda J. Song, Chaoping P. Li, and Liangding Jia (2008): How Do I Trust Thee? The EmployeeOrganization Relationship, Supervisory Support, and Middle Manager Trust in the Organization, Human Resource Management, 47 (1): 111-132.

Zwick, Rami and Xiao-Ping Chen (1999): What Price Fairness? A Bargaining Study, Management Science, 45 (6): 804-823.

\section{Biographies}

Prof. Dr. Markus Göbel holds the Chair for Theories of the Firm and Research Methods of Business Administration at Helmut Schmidt University, Hamburg Germany. His research interest lies in organization theories, microfoundation of strategic management, reciprocity as well as public management and (inter-) organizational governance and design. His research has appeared in such journals as Venture Capital, Scandinavian Journal of Management, Journal of Applied Behavioral Science and others.

Prof. Dr. Rick Vogel is Professor of Public Management \& Public Policy at Zeppelin University in Friedrichshafen, Germany. His main research interests include public administration, management control, organizational behavior and the sociology of science. He regularly publishes his research findings in international journals such as American Review of Public Administration, International Journal of Management Reviews, Organization Studies, Public Administration, and Research in the Sociology of Organizations.

Prof. Dr. Christiana Weber holds the Chair for Management and Organizational Behavior at the Leibniz University Hanover, Germany. Christiana Weber researches and consults at the intersection of social network theory, innovation management, and (social) entrepreneurship. Further, her research interest lies in organization theories, reciprocity as well as (inter-)organizational learning and knowledge transfer. Her research has appeared in such journals as Journal of Business Venturing, Scandinavian Journal of Management, Journal of Engineering and Technology Management, and others. 